\title{
Trust And Investments Across Cultures
}

Thomas Berry, (Email: tberry@depaul.edu), DePaul University

Omur Suer, (Email: osuer@gsu.edu.tr), Galatasaray University, Turkey

\begin{abstract}
ABSRTACT
This study uses survey data to examine notions of trust relative to investments and perceived risk. Rather than using nation cross-sectional household survey data we target a specific group across four distinct cultures. We survey graduate business students in four countries (Turkey, Bahrain, Czech Republic, and the USA). We attempt to gauge investor perceptions about trust and the potential impact of trust on equity investing. The groups are fairly homogeneous in terms of education and relative social and economic status leaving cultural differences as the main source of observed response differences.
\end{abstract}

Keywords: Trust, Investments, Risk, Culture, Equity

\section{INTRODUCTION}

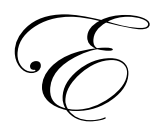

conomists as early as Adam Smith ${ }^{1}$ have recognized a role for trust in economic activity. More recently, Arrow (1972, 1974), Fukuyama (1995) and others have linked trust to social capital and economic success. Hong, Kubik and Stein (2004) show that trust and social interaction levels impact equity values. Guiso, Sapienza and Zingales (2005) state that in deciding whether to buy stocks investors factor in trust as a perception of risk. The perception of this risk depends not only on the characteristics of a particular firm and the institutions and markets where it is traded, but also of the uniqueness of the particular investor. Cultural factors that individuals share may impact their participation in the market, and Guiso, Sapienza, and Zingales focus on trust to explain differences in stock market participation across individuals and across countries. Bohnet and Zeckhauser (2004) examine whether the decision to trust a stranger is equivalent to taking a risky bet, or if a trust decision entails an additional risk premium to balance the costs of trust betrayal. They show that the decision to trust a stranger requires a greater risk premium than an otherwise equivalently risky bet done by lottery. It is apparent that trust is an important factor in economic activity and may be an underlying factor in some of the observable market 'anomalies' such as: varying participation rates (Guiso, Sapienza and Zingales (2005)), home country bias (French and Poterba (1991)), familiarity bias (Huberman (2001)), and possibly pricing questions such as the role of dividends, excess volatility, etc.

This study uses survey data to look at trust relative to investments and perceived risk. Rather than using national cross-sectional household survey data we target a specific group across four distinct cultures. Our survey uses graduate business students in four countries (Turkey, USA, Czech Republic, and Bahrain) to gauge investor perceptions about trust and the potential impact of trust on equity investing. This group is fairly homogeneous in terms of education, particularly of basic economic concepts, as well as social status and living standards - at least relative to cross-sectional national averages. Cultural and religious differences remain. ${ }^{2}$

\footnotetext{
${ }^{1}$ The Theory of Moral Sentiments

$\underline{2}$ Alesina and La Ferrara (2000) find that religious beliefs and ethnic backgrounds do not have a significant impact on trust within the U.S., we suspect this is due to the dominance of a shared culture and do not expect this to hold across cultures.

3 The question is: "Generally speaking, would you say that most people can be trusted or that you have to be very careful in dealing with people?" Individuals could answer (a) most people can be trusted (b) one has to be very careful with other people (c) I don't know. The percetage reporting (a) is used as an overall measure of trust.
} 
The surveys collect demographic data and use the standard question from the World Values Survey ${ }^{3}$ to determine levels of trust on a country wide basis. To compare differences across individuals the Social Values Orientation Scale developed by Yamagishi (1986) is used. The Social Values Orientation Scale (SVOS) is an index based on five questions about trust. In addition, we ask some specific questions related to trust and investments and we ask for the participant's view of the trustworthiness of the 14 major world areas for investing.

In the following section we present demographic data on the survey participants and data about their views on participating in equity markets. Section III compares trust levels across nationalities and gender. Section IV evaluates the respondents' views about trust in local and foreign firms, firms that pay dividends, and whether respondents consider trust when investing and if more trust is related to risk. We also rank the respondents' views about trust across the world. The final section contains a summary.

\section{DEMOGRAPHICS.}

In this section we present data on the nationality and ages of the respondents. All of the respondents were either enrolled in or had completed and MBA degree or masters in economics. There were a total of 498 respondents who were relatively evenly divided by nationality and gender. The breakdown by nationality and gender is shown in Table 1. In Table 2 we see that the current and planned participation in the stock market is roughly equivalent across respondents from Turkey, Bahrain, and the Czech Republic but is significantly higher in the U.S. For the total sample about $70 \%$ said they do or plan to invest in equities.

Table 1

Demographics

\begin{tabular}{|c|c|c|}
\hline & Number of respondents & Mean age \\
\hline \multicolumn{3}{|l|}{ Turkey } \\
\hline Male & 71 & 30.7 \\
\hline Female & 63 & 32.4 \\
\hline \multicolumn{3}{|c|}{ Czech Republic } \\
\hline Male & 56 & 29.5 \\
\hline Female & 61 & 28.62 \\
\hline \multicolumn{3}{|l|}{ Bahrain } \\
\hline Male & 64 & 29.61 \\
\hline Female & 56 & 28.91 \\
\hline \multicolumn{3}{|l|}{ U.S. } \\
\hline Male & 77 & 31.19 \\
\hline Female & 50 & 27.55 \\
\hline
\end{tabular}

\section{TRUST LEVELS}

We used two measures to determine the level of trust. The first is the standard question from the World Values Survey. The question is "Generally speaking, would you say that most people can be trusted or that you have to be very careful in dealing with people?". The responses are given in Table 3 below. The percentages for the groups that chose "Most people can be trusted" are relatively similar (20-30\%) but with two distinct differences. Most strikingly are the relatively high level of trust by the Czech women and the zero responses for both the men and women from Bahrain. 
Table 2

Equity Market Participation

\begin{tabular}{|c|c|c|c|c|}
\hline & Yes & No & $\begin{array}{l}\text { Not now, but plan to } \\
\text { in the future }\end{array}$ & $\begin{array}{c}\text { Yes, but only in } \\
\text { mutual funds }\end{array}$ \\
\hline \multicolumn{5}{|l|}{ Turkey } \\
\hline Male & 25 & 25 & 9 & 12 \\
\hline Female & 31 & 22 & 7 & 3 \\
\hline \multicolumn{5}{|c|}{ Czech Republic } \\
\hline Male & 15 & 22 & 16 & 3 \\
\hline Female & 15 & 20 & 22 & 4 \\
\hline \multicolumn{5}{|l|}{ Bahrain } \\
\hline Male & 27 & 21 & 8 & 8 \\
\hline Female & 5 & 20 & 18 & 13 \\
\hline \multicolumn{5}{|l|}{ U.S. } \\
\hline Male & 37 & 14 & 18 & 8 \\
\hline Female & 20 & 8 & 15 & 6 \\
\hline Totals & 175 & 152 & 113 & 57 \\
\hline Percentage & $35.14 \%$ & $30.52 \%$ & $22.69 \%$ & $11.45 \%$ \\
\hline
\end{tabular}

Table 3

Trust Levels with the World Values Survey question

\begin{tabular}{|c|c|c|c|c|}
\hline & $\begin{array}{c}\text { Most people can be } \\
\text { trusted }\end{array}$ & $\%$ & $\begin{array}{c}\text { You have to be very } \\
\text { careful }\end{array}$ & I don't know \\
\hline \multicolumn{5}{|l|}{ Turkey } \\
\hline Male & 17 & 23.9 & 43 & 11 \\
\hline Female & 16 & 25.4 & 41 & 6 \\
\hline \multicolumn{5}{|c|}{ Czech Republic } \\
\hline Male & 16 & 28.6 & 40 & 0 \\
\hline Female & 29 & 47.5 & 30 & 2 \\
\hline \multicolumn{5}{|l|}{ Bahrain } \\
\hline Male & 0 & 0 & 61 & 3 \\
\hline Female & 0 & 0 & 51 & 5 \\
\hline \multicolumn{5}{|l|}{ U.S. } \\
\hline Male & 18 & 23.4 & 55 & 4 \\
\hline Female & 10 & 20 & 36 & 4 \\
\hline \multicolumn{5}{|l|}{ Total } \\
\hline Male & 51 & & 159 & 18 \\
\hline Female & 55 & & 158 & 17 \\
\hline All & 106 & $21.3 \%$ & 357 & 35 \\
\hline
\end{tabular}

While this measure of trust gives a reliable overall indicator of the trust level of a group for cross-cultural comparisons, we wanted a variable which could assume a greater range of values. To that end we included questions to construct the Social Values Orientation Scale developed by Yamagishi (1986). This index can range in value from 5 for lowest trust to 25 for highest trust. The ranges, means, and standard deviations for this index are reported in Table 4 by nationality and gender. The lowest levels of trust are again the respondents from Bahrain and 
the highest is for Czech women. Pairwise comparisons by nationality show that significant (at 5\%) differences exist between the U.S. and all the other countries, and between the Czech Republic and Bahrain. Over all respondents the average trust index is 14.37 for those who invest in the market while it is only 13.37 for those who do not, which is statistically significant at the $1 \%$ level,

Table 4

Trust Index

\begin{tabular}{|c|c|c|c|c|}
\hline \multicolumn{5}{|c|}{$1=$ strongly agree } \\
\hline & Mean & Standard Deviation & Range & Range cont. \\
\hline Turkey & & & Min & Max \\
\hline Male & 13.71 & 2.93 & 8 & 20 \\
\hline Female & 13.62 & 2.99 & 7 & 19 \\
\hline \multicolumn{5}{|c|}{ Czech Republic } \\
\hline Male & 14.43 & 3.14 & 9 & 20 \\
\hline Female & 16.31 & 3.22 & 11 & 23 \\
\hline \multicolumn{5}{|l|}{ Bahrain } \\
\hline Male & 12.51 & 2.57 & 8 & 18 \\
\hline Female & 13.02 & 3.1 & 8 & 18 \\
\hline \multicolumn{5}{|l|}{ U.S. } \\
\hline Male & 14.38 & 3.02 & 9 & 19 \\
\hline Female & 13.86 & 3.55 & 7 & 19 \\
\hline
\end{tabular}

\section{TRUST AND INVESTMENTS}

In this section we examine the responses to five questions about trust and investments. The first question is "Trust in a company is a factor I consider when investing". The highest trust ranking is among U.S. women and the lowest is among U.S. men but all groups ranked it highly. Mean responses for this question are given in Table 5.

Table 5

Trust in a company is a factor I consider which investing

$1=$ strongly agree $\quad 5=$ strongly disagree

\begin{tabular}{|c|c|c|}
\hline & \multicolumn{2}{|c|}{ j- stioligiy uisagied } \\
\hline & Mean & Standard deviation \\
\hline \multicolumn{3}{|l|}{ Turkey } \\
\hline Male & 1.9 & .76 \\
\hline Female & 2.05 & .87 \\
\hline \multicolumn{3}{|c|}{ Czech Republic } \\
\hline Male & 2 & .93 \\
\hline Female & 1.84 & .84 \\
\hline \multicolumn{3}{|l|}{ Bahrain } \\
\hline Male & 1.83 & .66 \\
\hline Female & 1.73 & .65 \\
\hline \multicolumn{3}{|l|}{ U.S. } \\
\hline Male & 2.08 & .94 \\
\hline Female & 1.63 & .70 \\
\hline
\end{tabular}


The second question is whether trust is related to risk, the question is "The more I trust the company the less risky I perceive it to be". Responses are presented in Table 6 and the mean responses are between agree and neutral.

Table 6

The more trust the company, the less risky I perceive it to be

\begin{tabular}{|c|c|c|}
\hline \multicolumn{2}{|c|}{$1=$ strongly agree } & $5=$ strongly disagree \\
\hline & Mean & Standard Deviation \\
\hline \multicolumn{3}{|l|}{ Turkey } \\
\hline Male & 2.31 & .96 \\
\hline Female & 2.15 & .81 \\
\hline \multicolumn{3}{|c|}{ Czech Republic } \\
\hline Male & 2.43 & .88 \\
\hline Female & 2.35 & .99 \\
\hline \multicolumn{3}{|l|}{ Bahrain } \\
\hline Male & 2.28 & .75 \\
\hline Female & 2.15 & .62 \\
\hline \multicolumn{3}{|l|}{ U.S. } \\
\hline Male & 2.32 & .87 \\
\hline Female & 2.25 & 1.0 \\
\hline
\end{tabular}

The third question concerns dividends and asks "I trust companies that pay dividends more than those that don't". The responses generally center around neutral with the greatest agreement among Czech women and the least with U.S. men. For all nationalities women showed greater agreement than men but most of the differences are fairly small. These responses are in Table 7.

Table 7

I trust companies that pay dividends more than those that do not.

\begin{tabular}{|c|c|c|}
\hline \multicolumn{2}{|c|}{$1=$ strongly agree } & $5=$ strongly disagree \\
\hline Turkey & Mean & Standard deviation \\
\hline Male & 2.89 & .75 \\
\hline Female & 2.81 & .95 \\
\hline \multicolumn{3}{|c|}{ Czech Republic } \\
\hline Male & 3.11 & .84 \\
\hline Female & 2.67 & .99 \\
\hline \multicolumn{3}{|l|}{ Bahrain } \\
\hline Male & 2.98 & .79 \\
\hline Female & 2.8 & .88 \\
\hline \multicolumn{3}{|l|}{ U.S. } \\
\hline Male & 3.13 & .81 \\
\hline Female & 3.04 & .88 \\
\hline
\end{tabular}

The fourth question looks at the issue of familiarity bias by asking "I have more trust in local or familiar firms". Huberman's (2001) explanation for the documented lack of international diversification and high levels of local investing is simple, “...people simply prefer to invest in the familiar." (page 659) The responses, shown in Table 8, center around neutral and show the greatest agreement with U.S. respondents and the least with Czech 
respondents. Anecdotal evidence from interviews with Czech participants indicated that the market is considered too thin and subject to potential manipulation to be trustworthy. Pairwise comparisons show the U.S. responses to be significantly (at the 5\% level) from all other countries and significantly different between the Czech Republic and Bahrain.

Table 8

I have more trust in local or familiar companies $1=$ strongly agree $\quad 5=$ strongly disagree

\begin{tabular}{|c|c|c|}
\hline Turkey & Mean & Standard deviation \\
\hline Male & 2.96 & .99 \\
\hline Female & 2.94 & 1.0 \\
\hline \multicolumn{3}{|c|}{ Czech Republic } \\
\hline Male & 3.81 & .88 \\
\hline Female & 2.31 & .99 \\
\hline \multicolumn{3}{|l|}{ Bahrain } \\
\hline Male & 2.81 & .85 \\
\hline Female & 2.86 & .77 \\
\hline \multicolumn{3}{|l|}{ U.S. } \\
\hline Male & 2.75 & .97 \\
\hline Female & 2.24 & .66 \\
\hline
\end{tabular}

The final question deals with the role of home country bias. French and Poterba (1991) show that the lack of international diversification implies that investors expect returns to be significantly higher in their home country. Alternatively, one could say view the risk to be significantly lower in their home country and demand a significant risk premium for international investments. In Table 9 we address this question directly by asking "Regardless of familiarity or location, I have less trust in foreign firms."

Table 9

Regardless of familiarity or location, I have less trust in foreign companies $1=$ strongly agree $5=$ strongly disagree

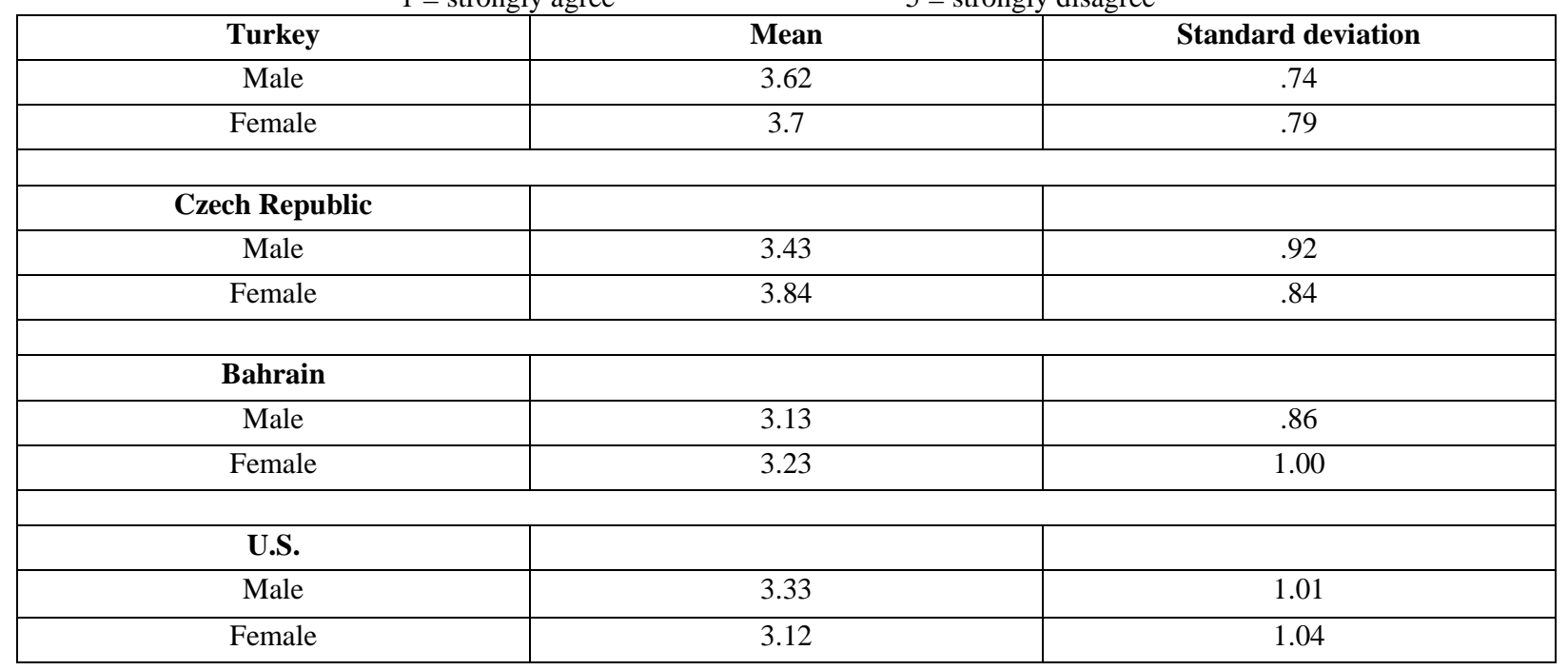


Of course, relative to the U.S. these countries have limited equity markets and are essentially forced to diversify across borders. To see if they view trust to be similar in various regions of the world we asked respondents to rank fourteen major world areas by perceived risk. The results of this question are reported in Table 10. Based on average rankings both the U.S. and Czech respondents rank the U.S. as the most trustworthy, while those from Turkey and Bahrain rank Western Europe to be the most trustworthy. The most trustworthy area based on total rankings is Canada. The lowest overall trust is given for Africa with both Turkish and Bahraini respondents ranking it lowest. The U.S. respondents ranked the Middle East as the least trustworthy and respondents from the Czech Republic ranked Russia the least trustworthy.

Table 10

Trust by World Region

\begin{tabular}{|c|c|c|c|c|}
\hline \multicolumn{5}{|c|}{ Mean rankings } \\
\hline Wurkey & Czech Republic & Bahrain & U.S. \\
\hline U.S & 3.93 & 3.91 & 4.3 & 3.68 \\
\hline Canada & 3.74 & 3.98 & 4.01 & 3.94 \\
\hline E. Europe & 3.92 & 3.94 & 4.13 & 2.87 \\
\hline Russia & 2.95 & 2.97 & 2.96 & 2.65 \\
\hline M. East & 2.15 & 1.82 & 3.07 & 1.88 \\
\hline E. Asia & 2.01 & 2.04 & 3.32 & 2.82 \\
\hline Australia & 2.63 & 2.63 & 3.94 & 3.8 \\
\hline Africa & 3.59 & 3.78 & 2 & 1.74 \\
\hline C. America & 1.86 & 1.88 & 2.36 & 1.99 \\
\hline S. America & 2.17 & 2.38 & 2.7 & 2.13 \\
\hline Near East & 2.1 & 2.54 & 2.7 & 2.12 \\
\hline China & 2.24 & 2.5 & 2.32 & 2.38 \\
\hline India & 2.62 & 2.54 & 2.5 & 2.41 \\
\hline
\end{tabular}

\section{SUMMARY}

This paper reports the results of a survey of 498 business students in four distinct cultures (Turkey, Bahrain, the Czech Republic, and the U.S.) on their attitudes toward trust and equity investing. A constructed trust index showed a statistically significantly higher level of trust for those who participate in the market versus those who do not and, on average, women are shown to be more trusting than men. Statistically significant differences exist in trust levels across countries and by gender but generally it did not seem to have a major impact on their views of local or familiar firms versus foreign firms nor on the trustworthiness of dividend paying firms. Views of the trustworthiness of certain areas of the world were generally consistent and possibly slightly skewed by past national relationships and current political tensions.

\section{REFERENCES}

1. Alesina and E. La Ferrara (2000), Participation in Heterogeneous Communities. Quarterly Journal of Economics, \#115, pp. 847-904

2. Arrow, K. (1972), Gifts and Exchanges, Philosophy and Public Affaires, I, pp:343-362

3. Arrow, K. (1974), The Limits of Organization, W.W. Norton, New York

4. Bohnet, Iris and Richard Zeckhauser (2004), Trust, Risk and Betrayal, Journal of Economic Behavior \& Organization, Vol:55, pp:467-484

5. Coleman, James S. (1988), Social Capital in the Creation of Human Capital, American Journal of Sociology, Vol :94, pp :95-120

6. Coleman, James (1990), Foundations of Social Theory, Cambridge, MA.: Harvard University Press

7. French, Kenneth R. and James M. Poterba (1991), Investor Diversification and International Equity Markets, American Economic Review, Vol:81, Issue:2, pp:222-226 
8. $\quad$ Fukuyama, F. (1995), Trust, New York: Free Press

9. Gambetta, Diego, ed., (1988) Trust: Making and Breaking Cooperative Relations, Cambridge, U.K.: Basil Blackwell

10. Glaeser, E., D. Laibson, J. Scheinkman and C.L. Soutter, What Is Social Capital ? The Determinants of Trust and Trustworthiness, NBER Working Paper No:7216, 1999

11. Glaeser, Edward L. ,et al. (2000), Measuring Trust, Quarterly Journal of Economics, Vol:115, Issue 3, p:811, 36 pages

12. Glaeser, Edward L., David Laibson, Bruce Sacerdote (2000), The Economic Approach to Social Capital, NBER Working Paper No:7728, http://www.nber.org/papers/w7728

13. Guiso, Luigi; Paola Sapienza and Luigi Zingales (2005), Trusting The Stock Market, WP 11648, NBER

14. Hong, Harrison; Jeffrey D. Kubik and Jeremy C. Stein (2004), Social Interaction and Stock-Market Participation, The Journal of Finance, Vol. LIX, No:1, February, pp:137- 163

15. Huberman, Gur (2001), Familiarity Breeds Investment, The Review of Financial Studies, Vol:14, No:3, pp:659-680

16. Sobel, Joel (2002), Can We Trust Social Capital”, Journal of Economic Literature, Vol: XL, pp139-154

17. Tversky and C. Heath (1991), Preferences and Beliefs: Ambiguity and Competence in Choice Under Uncertainty, Journal of Risk and Uncertainty, Jan. 1991, \#4, pp. 5-28.

\section{NOTES}

